\title{
In-Vitro Screening and Molecular Characterization of the Double Haploids for the Bacterial Blight Resistance Genes $\mathrm{Xa21}$ and $\mathrm{Xa13}$
}

\author{
Mridhu Sharma*, A.K. Singh and R.K. Salgotra \\ Department of School of Biotechnology, Sher-e-Kashmir University of Agricultural Sciences \\ \& Technology of Jammu, Chatha, Jammu and Kashmir- 180009, India \\ *Corresponding author
}

\section{A B S T R A C T}

Conventional breeding involves time taking procedure for pyramiding of genes and screening of crops for the same. Double haploid (DH) production can reduce the time of production of resistant crops in less time period. Twenty one plants that survived after the

Keywords

breeding genotypes homozygous

Article Info

Accepted:

15 December 2019 Available Online: 20 January 2020 hardening procedure were screened phenotypically and molecularly for BB resistant genes. When the DH plants were infected with Xoo, they showed four plants (nineteen percent) showed resistant reaction, twelve plants (fifty seven percent) showed moderately resistant reaction, four plants (nineteen percent) were moderately susceptible reaction and one plant (five percent) showed susceptible reaction. The primer pairs, Xa21 pTA248 and xa13prom showed good polymorphism between the resistant and susceptible genotypes with an amplicon size of 1000bp and 500bp in the resistant genotypes of Xa21 and $x a 13$ and 650bp and 250bp amplicon in the susceptible genotypes respectively, while heterozygous individuals amplified both the two fragments Parent PAU148 (PA) is heterozygous as they amplified both the strands. Parent ranbir basmati (RB) has only recessive genes for both $X a 21$ and $x a 13$ genes. Except for plant number 8 and 21that are susceptible, all the plants have dominant gene for $X a 21$ and are homozygous. Except for plant number 8 that is heterozygous and plant number 21 that is susceptible, all the plants have dominant gene for xa13 and are homozygous.

\section{Introduction}

As a staple food of half of the world population, rice (Oryza sativa .L) stands as a model for plant genomic research with approximately 2.6 thousand kilograms per hectare (Anonymous, 2019). Bacterial blight caused by Xanthomonas oryzae pv.oryzae $(X o o)$, the oldest known bacterial disease of rice (Naqvi et al., 2014) by invading xylem is a non-spore forming rod shaped colony forming gram negative bacteria with the size of $0.55-0.75 \times 1.35-2.17 \mu \mathrm{m}$. The bacterial colonies are light yellow, circular, convex and smooth and produce a yellow coloured water soluble pigment. A race is a subgroup within a species, distinguished from other races by virulence and not by morphology. Studies of genetic mapping of 40 races have lead to the identification of more than $40 \mathrm{Xa}$ resistance 
(R) gene loci (Martin et al., 2003), nine being Xa1, Xa3/Xa26, xa5, Xa10, xa13, Xa21, Xa23, xa25, and Xa27 (Wang et al., 2014), mostly derived from Oryza sativa. The different races, however, have not been clearly defined with the specific reactions being assigned to each rice variety/cultivar (Niño-Li et al., 2006, Kim et al., 2015).

A type III protein secretion system exists in this bacterium to directly inject virulence factors into the host (Furutani et al., 2009). A clear understanding of the molecular mechanisms in the host resistance to pathogens is essential for prerequisite for the better design of control strategies for rice BB. Even though many effective resistance genes have been identified against BB, unfortunately, it has been observed that resistance conferred by single resistance gene has broken down in many places and hence pyramiding two or more genes conferring resistance into a single genetic background has been advocated (Sundaram et al, 2014).

The conventional breeding involves phenotype-based selection, is time taking, has undesirable linkages that prevent the cultivar being improved from promoting the performance of the original recurrent parent (Hasan et al., 2015) and even more time taking for transferring the recessive traits. It is at many times impossible for pyramiding multiple BB resistance genes, marker-assisted gene pyramiding has been widely adopted (Dokku et al, 2013). This study is conducted to characterize the resistance of $\mathrm{DH}$ by gene combination $\mathrm{Xa21}$ and $x a 13$.

\section{Materials and Methods}

\section{Plant material}

The plant material used for the following study was the tissue culture raised plants in the lab of Sher-e-Kashmir University of
Agricultural Science and Technology of Jammu, Chatha, Jammu and Kashmir, India from the $\mathrm{BC}_{2} \mathrm{~F}_{1}$ population produced by crossing Ranbir Basmati and PAU148 (containing $\mathrm{Xa21}$ and $x a 13$ ). The cultures were initiated from the heterozygous $\mathrm{BC}_{2} \mathrm{~F}_{1}$ parents in the $\mathrm{N}_{6}$ media and then regenerated in the MS media. Thirty four plants survived during the process of which twenty-one plants were observed to be doubled haploids by checking the fertility percentage.

\section{Screening for BB resistance}

A virulent $\mathrm{BB}$ pathogen, incompatible with rice genotypes carrying Xa21 and xal3 either singly or in combinations, were isolated collected from the farm of Sher-e-Kashmir University of Agricultural Science and Technology of Jammu, Chatha, Jammu and Kashmir, India using nutrient agar medium.

\section{Phenotypic screening}

Then Xanthomonas oryzae (Xoo) was inoculated in nutrient broth till $\mathrm{OD}_{600}$ became 0.5 or CFU (colony forming unit) was $10^{9} \mathrm{cfu}$ 's $/ \mathrm{ml}$. The isolated Xoo was used for resistance screening of forty days old plants following the leaf clipping technique of Kauffman et al., (1973). Observations were taken both by measuring the lesion length and recording the disease score following the standard evaluation scale Yuan et. al (2016).

\section{Molecular screening}

In vitro amplification using Polymerase Chain Reaction (PCR) was carried out using four sets of primer pairs, two each for Xa21 and $x a 13$ gene-linked markers viz. pTA248 and $x a 13$ promoter genes respectively (Table 1 ). The marker, pTA248, specific for the resistant allele of Xa21 was used as the functional marker for the gene (Salgotra et al, 2012) and based on InDel polymorphism in the promoter 
region of $0 s 8 N 3$, gene for $x a 13$ (Chu et al, 2006). It was performed in a 96 well Universal Gradient Thermal Cycler (EPPENDORF AG, Hamburg, Germany) subjected to the thermal profile as given in Table 2 for confirmation of $X a 21$ and $x a 13$ genes and the amplicons are checked on $2 \%$ agarose gel.

\section{Results and Discussion}

\section{Phenotypic screening}

When plants were infected with Xoo, they showed results as shown in Table 4 . Of the twenty one doubled haploid plants, four plants showed resistant reaction (Figure 2b), twelve plants showed moderately resistant reaction (Figure 2c), four plants showed moderately susceptible reaction (Figure 2d) and one plant showed susceptible reaction (Figure 2e) i.e. nineteen percent of the plants are resistant, fifty seven percent are moderately resistant, nineteen percent are moderately susceptible and five percent are susceptible (Figure 3).

\section{Molecular screening}

The primer pair, Xa21 pTA248 and xa13prom showed good polymorphism between the resistant and susceptible genotypes with an amplicon size of 1000bp and 500bp in the resistant genotypes of $X a 21$ and $x a 13$ and 650bp and 250bp amplicon in the susceptible genotypes respectively, while heterozygous individuals amplified both the two fragments Parent PAU148 (PA) is heterozygous as they amplified both the strands.

Parent ranbir basmati (RB) has only recessive genes for both $X a 21$ and $x a 13$ genes. Except for plant number 8 and 21that are susceptible, all the plants have dominant gene for $\mathrm{Xa21}$ and are homozygous (Figure 5a). Except for plant number 8 that is heterozygous and plant number 21that is susceptible, all the plants have dominant gene for $x a 13$ and are homozygous (Figure 5b).

Table.1 Primer sequences for $\mathrm{Xa21}$ and $\mathrm{xa} 13$

\begin{tabular}{|l|l|l|}
\hline Gene & Primer name & Sequence \\
\hline $\boldsymbol{X a 2 1}$ & PTA248 (F) & 5'-AGACGCGGAAGGGTGGTTCCCGGA-3' \\
\hline & PTA248 (R) & 5'-AGACGCGGTAATCGAAAGATGAAA-3' \\
\hline $\boldsymbol{x a 1 3}$ & xa13-prom (F) & 5'-GGCCATGGCTCAGTGTTTAT-3' \\
\hline & xa13-prom (R) & 5'-GAGCTCCAGCTCTCCAAATG-3' \\
\hline
\end{tabular}

Table.2 Thermal profile used for amplification of Xa21 and $x a 13$ genes

\begin{tabular}{|c|c|c|c|c|}
\hline \multirow[b]{2}{*}{ Steps } & \multirow[b]{2}{*}{ Cycles } & \multirow[b]{2}{*}{ Temperature } & \multicolumn{2}{|l|}{ Duration } \\
\hline & & & $\begin{array}{l}\text { Xa21 } \\
(\text { pTA248) }\end{array}$ & $\begin{array}{l}x a 13 \\
\text { (xa13 promoter) }\end{array}$ \\
\hline Denaturation & $\rightarrow 1$ & $94^{\circ} \mathrm{C}$ & $4 \min$ & $4 \mathrm{~min}$ \\
\hline Denaturation & & $94^{\circ} \mathrm{C}$ & $30 \mathrm{sec}$ & $1 \mathrm{sec}$ \\
\hline Annealing & -30-35 cycles & $55^{\circ} \mathrm{C}$ & $30 \mathrm{sec}$ & $1 \mathrm{sec}$ \\
\hline Extension & & $72^{\circ} \mathrm{C}$ & $1 \mathrm{~min}$ & $1 \mathrm{~min}$ \\
\hline Final Extension & $\rightarrow 1$ & $72^{\circ} \mathrm{C}$ & $7 \mathrm{~min}$ & $7 \mathrm{~min}$ \\
\hline Hold & & $4^{\circ} \mathrm{C}$ & & \\
\hline
\end{tabular}


Table.3 The lesion length $(\mathrm{cm})$ of the doubled haploids

\begin{tabular}{|l|l|l|l|l|l|}
\hline S no. & Lesion length $(\mathbf{c m})$ & Reaction & S no. & Lesion length (cm) & Reaction \\
\hline DH1 & 14.5 & MS & DH13 & 5.4 & MR \\
\hline DH2 & 12.6 & MS & DH14 & 7.9 & MR \\
\hline DH3 & 11.0 & MS & DH15 & 5.9 & MR \\
\hline DH4 & 14.1 & MS & DH16 & 3.8 & R \\
\hline DH6 & 7.2 & MR & DH17 & 1.9 & R \\
\hline DH7 & 8.1 & MR & DH18 & 8.2 & MR \\
\hline DH8 & 17.6 & S & DH19 & 6.6 & MR \\
\hline DH9 & 7.5 & MR & DH20 & 5.8 & MR \\
\hline DH10 & 3.9 & R & DH21 & 8.2 & MR \\
\hline DH11 & 2.5 & R & DH22 & 7.1 & MR \\
\hline DH12 & 8.9 & MR & & & \\
\hline
\end{tabular}

*DH- Double haploids, R- resistant, MR- Moderately resistant, MS- Moderately susceptible and S- susceptible.

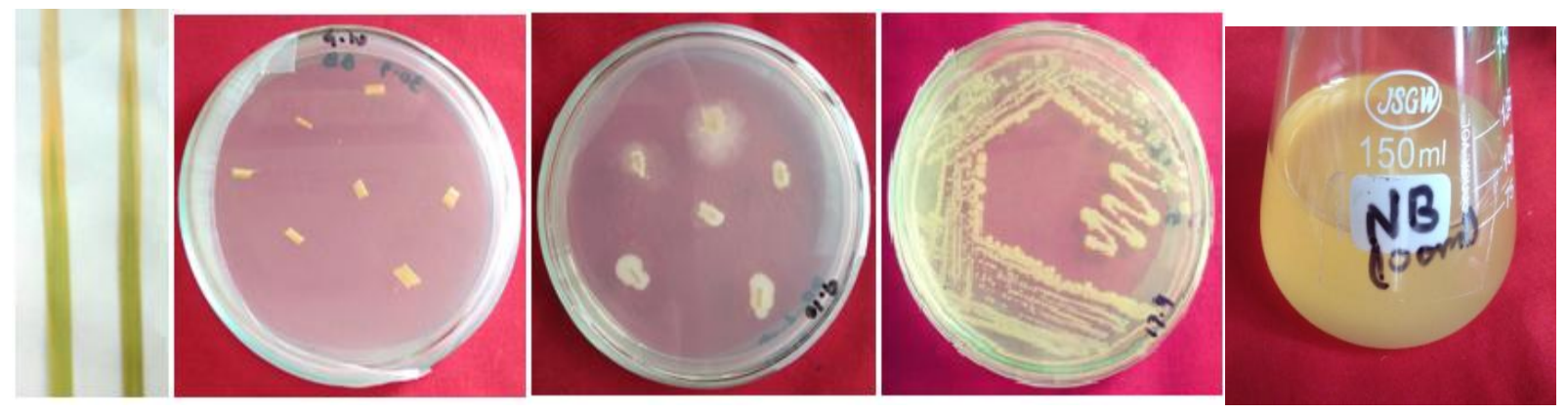

Figure.1 Isolation of BB virulent pathogen from the infected leaves.

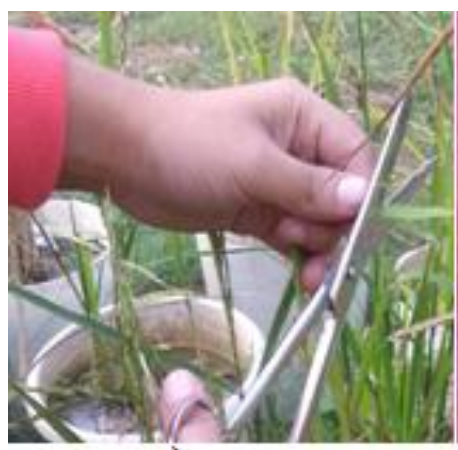

a)

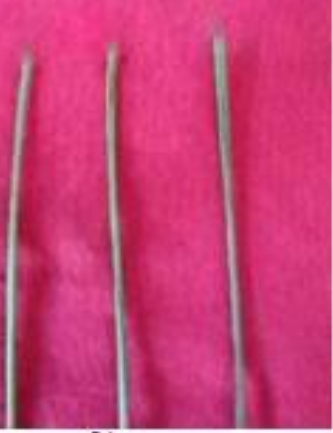

b)

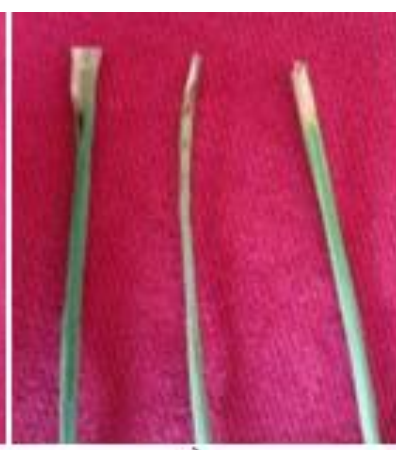

c)

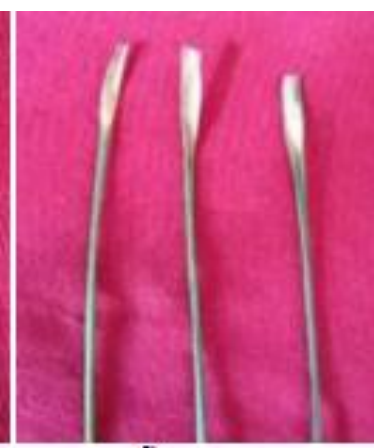

d)

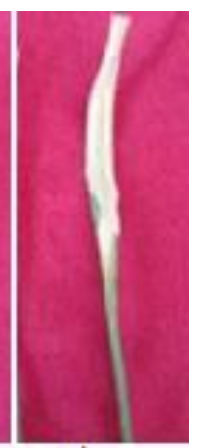

e)

Figure.2 a)Infection given to plants using leaf clipping technique and the result of infection after 8 weeks of inoculation: Leaves showing b)resistant reaction, c)moderately resistant reaction, d)moderately susceptible reaction and e) susceptible reaction. 


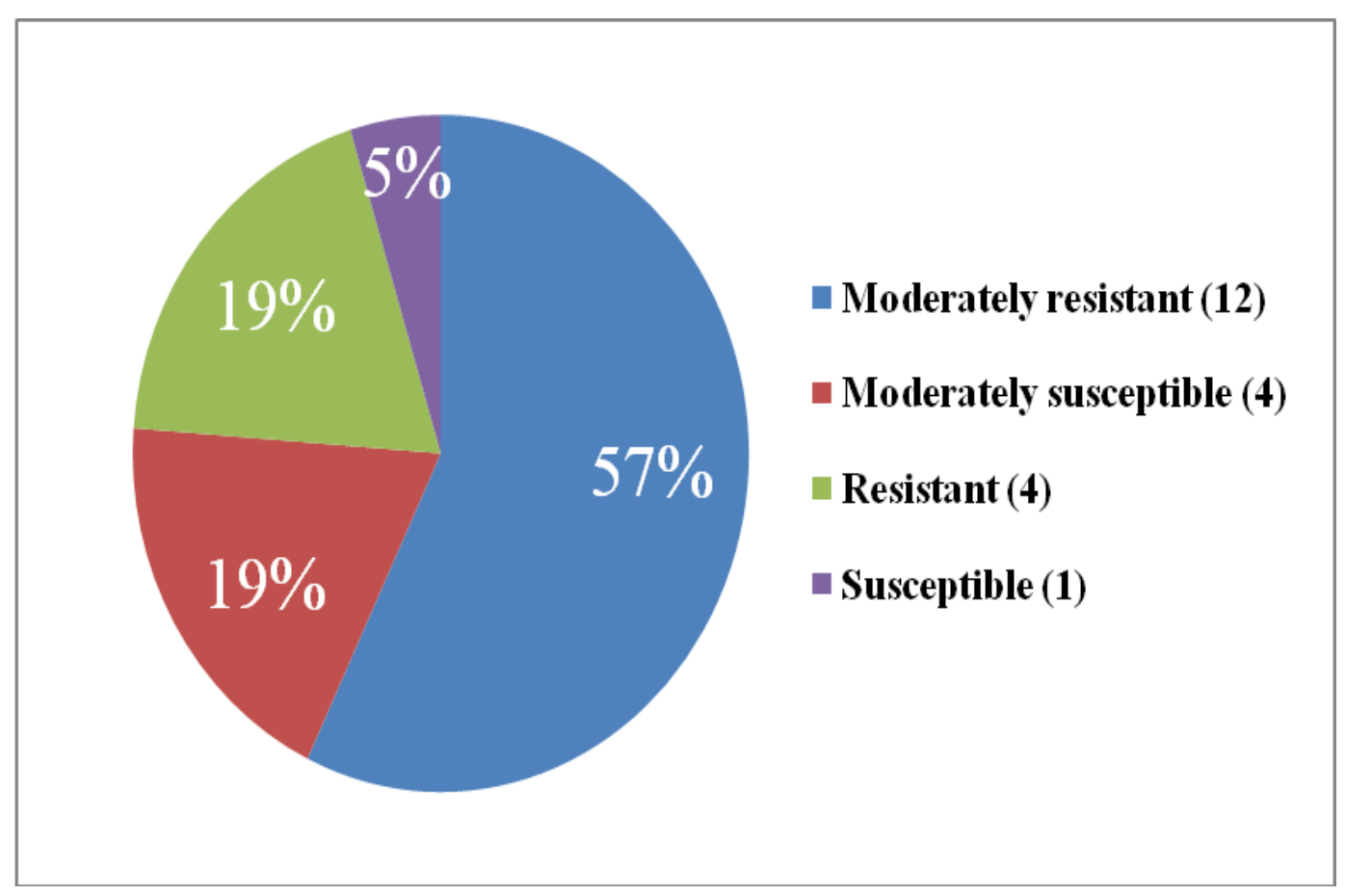

Figure.3 Pie chart showing the reaction based on lesion lengths.

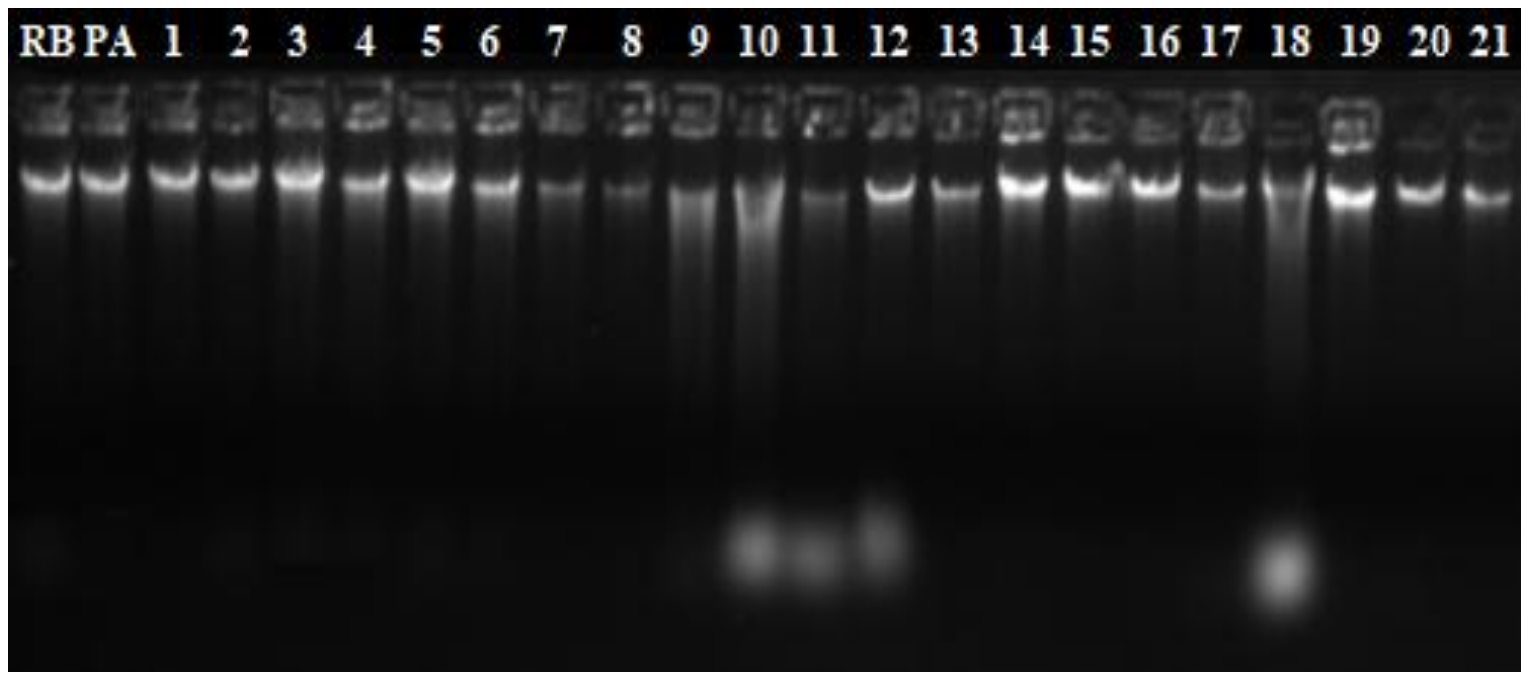

Figure.4 DNA isolation of doubled haploid plants 

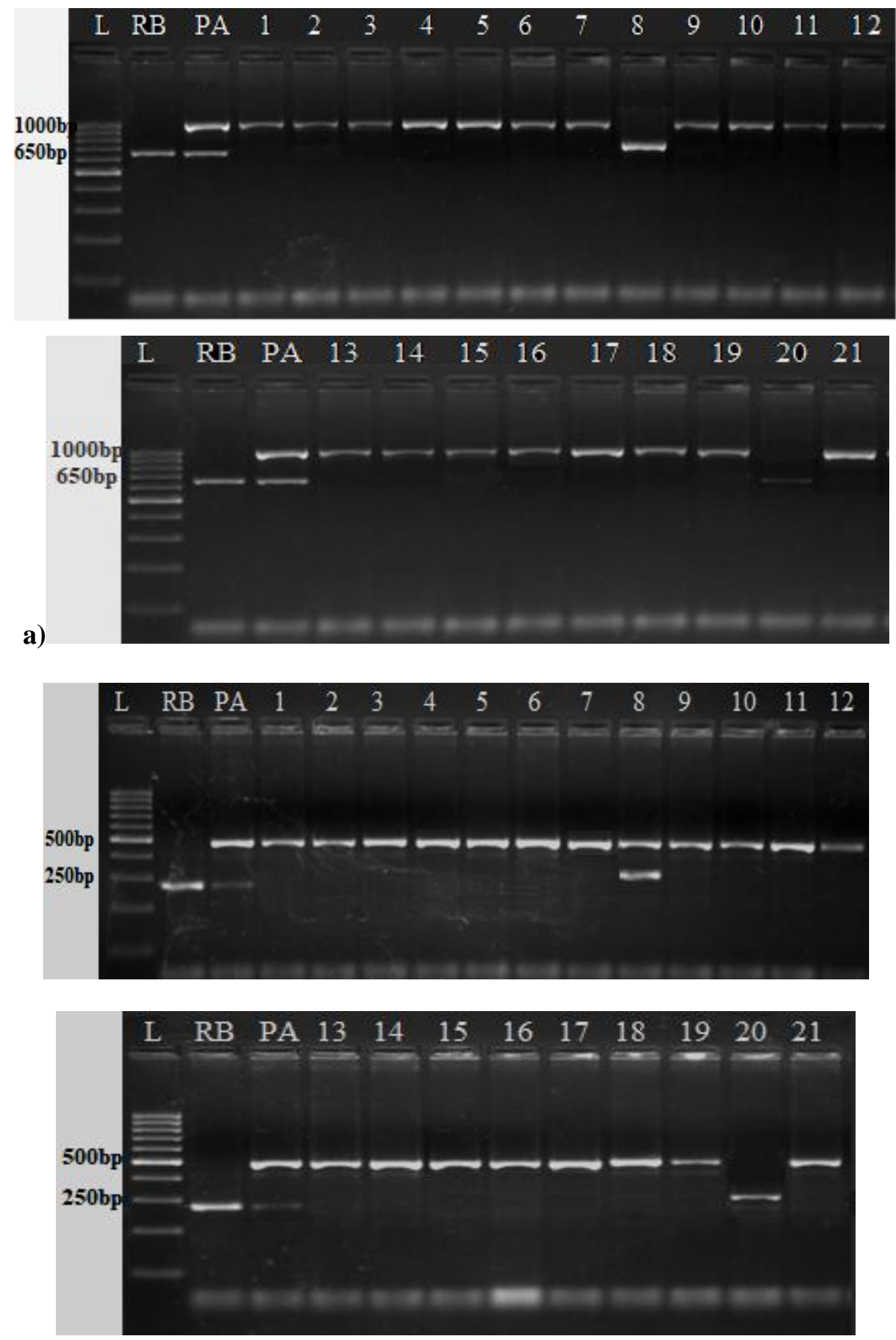

Figure.5 Molecular screening: a)amplification Xa21 gene and b) amplification of $x a 13$ gene.

The dominant gene $X a 21$, which provides broad spectrum resistance against Xoo strains among all the resistance genes that have been studied so far, is derived from wild rice, Oryza longistaminata. It is important to note that in the many rice breeding groups, the 
gene combination $\mathrm{Xa21}+x a 13+x a 5$ is widely deployed (Joseph et al, 2004). Among the resistance gene-combinations, gene pyramid lines $X a 21+x a 13+x a 5$ (all the genes having different mechanism of resistance), widely deployed previously have been highly suitable for deployment several locations across India (Shaik et al, 2014).

A simple PCR based functional marker specific for Xa21 i.e. pTa248 is available which displays amplicon length polymorphism (ALP) (Salgotra et al., 2011). Similar functional markers displaying ALP for $x a 13$ promoter, i.e. $0 s 8 N 3$ are also available. Arunakumari et al., (2016) reported the cross of Improved Samba Mahsuri (ISM) with MTU101012 was improved against the Xoo by presence of the $\mathrm{Xa21}$ gene. Gustave et al., (2011) showed that the presence of qBBR11-1in the cross between IR4 and Azucena is effective on all types of Xoo strains from Africa. This therefore indicates that this particular QTL is important for resistance to BLB.

\section{Acknowledgements}

Authors would like to thank Dr. R.K. Salgotra for providing seed material for the experiment. This experiment was financially supported by the school of biotechnology, Sher-e-Kashmir University of Agricultural Science and Technology of Jammu.

\section{References}

Anonymous. 2019. Annual yield of rice in India 1990-2019. Statista Research Department.

Arunakumari, K., Durgarani, C., Satturu, V., Sarikonda, K., Chittoor, P., and Vutukuri, B. 2016. Marker-assisted pyramiding of genes conferring resistance against bacterial blight and blast diseases into Indian rice variety
MTU1010. Rice Science. 23 (6):306316.

Chu, Z. H., Fu, B. Y., Yang, H., Xu, C. G., Li, Z. K., Sanchez, A., Park, Y. J., Bennetzen, J. L., Zhang, Q. F., Wang, S. P. 2006. Targeting xal3, a recessive gene for bacterial blight resistance in rice. Theor Appl Genet. 112(3): 455461.

Dokku, P., Das, K. M., Rao, G. J. N. 2013. Pyramiding of four resistance genes of bacterial blight in Tapaswini, an elite rice cultivar, through marker-assisted selection. Euphytica. 192(1): 8796.

Furutani, A., Takaoka, M., Sanada, H., Noguchi, Y., Oku, T., Tsuno, K., Tsuge, S. 2009. Identification of novel type III secretion effectors in Xanthomonas oryzae pv. oryzae. Molecular PlantMicrobe Interactions. 22(1), 96-106.

Gustave, D., Marie-Noëlle, N., Thierry, M., Casiana, C., Ambaliou, S., Alain, G. and Valerie, V. 2011. Evaluation of African Cultivated Rice Oryza glaberrima for Resistance to Bacterial Blight. Plant Disease. 95:441-447.

Hasan, M. M., Rafii, M.Y., Ismail, M. R. 2015. Marker-assisted backcrossing: a useful method for rice improvement. Biotechnology \& Biotechnological Equipment.Vol. 29, 2015, pp. 237-254.

Joseph, M., Gopalakrishnan, S., Sharma, R. K., Singh, V. P., Singh, A. K., Singh, N. K., Mohapatra, T. 2004. Combining bacterial blight resistance and basmati quality characteristics by phenotypic and molecular marker assisted selection in rice. Molecular Breeding. 13(4): 377-387.

Kauffman, H. E., Reddy, A. P. K., Hsieh, S. P.Y. and Merca, S. D. 1973. An improved technique for evaluating resistance of rice varieties to Xanthomonas oryzae. Plant Dis Rep. 57(6): 537-541.

Kim, S. M., Suh, J. P., Qin, Y., Noh, T. H., 
Reinke, R. F., Jena, K. K.2015. Identification and fine-mapping of a new resistance gene, Xa40, conferring resistance to bacterial blight races in rice (Oryza sativa L.). Theor Appl Genet. 128(10):1933-1943

Martin, G. B., Bogdanove, A. J., \& Sessa, G. 2003. Understanding the functions of plant disease resistance proteins. Annual Review of Plant Biology. 54(1), 23-61.

Naqvi, S. A. H., Perveen, R., Umer, U. D., Malik, O., Rehman, A., Wazeer, S. and Taha Majid, T. 2014. International Journal of Microbiology and Mycology. 2, 12-19.

Niño-Liu, D. O., Ronald, P. C., and Bogdanove, A. J. 2006. Xanthomonas oryzae pathovars: Model pathogens of a model crop. Molecular Plant Pathology. 7(5), 303-324.

Salgotra, R. K., Millwood, R. J., Agarwal, S., Steward, N. C. 2011. High throughput functional marker assay for detection of $X a / x a$ and $f g r$ genes in rice (Oryza sativa L.). Electrophoresis. 32(16): 2216-2222.

Shaik, H., Yugander, A., Balachiranjeevi, C. H., Pranathi, K., Anila, M., Mahadevaswamy, H. K., Kousik, B. V. N., Kumar, T. D., Reddy G. A.,
Bhaskar, S., Kumar V. A., Harika, G., Rekha, G., Laha, G. S., Viraktamath, B. C., Balachandran, S. M., Neeraja, C. N., Madhav, M. S., Mangrauthia, S. K., Bhadana, V. P., Sundaram, R. M. 2014. Development of durable bacterial blight resistant lines of Samba Mahsuri possessing Xa33, Xa21, Xa13 \& Xa5. Progressive Research. 9: 1224-1227.

Shanti, M. L., Shenoy, V.V., Devi, G. L., Kumar, V. M., Premalatha, P., Kumar, G. N., Shashidhar, H. E., Zehr, U. B. and Freeman, W. H. 2010. MarkerAssisted Breeding For Resistance To Bacterial Leaf Blight In Popular Cultivar And Parental Lines Of Hybrid Rice Journal of Plant Pathology. 92(2): 495-501.

Wang, C., Zhang, X., Fan, Y., Gao, Y., Zhu, Q., Zheng, C., Qin, T., Li, Y., Che, J., Zhang, M., Yang, B., Liu, Y., Zhao, K. 2014. $\mathrm{Xa23}$ is an executor $\mathrm{R}$ protein and confers broad-spectrum disease resistance in rice. Mol Plant.

Yuan, M., Ke, Y., Huang, R, Ma, L., Yang, Z., Chu, Z., Xiao, J., Li, X. and Wang, S. (2016) A host basal transcription factor is a key component of rice by TALE- carrying bacteria. Elife. 5: e 19605.

\section{How to cite this article:}

Mridhu Sharma, A.K. Singh and Salgotra. R.K. 2020. In-Vitro Screening and Molecular Characterization of the Double Haploids for the Bacterial Blight Resistance Genes Xa21 and Xa13. Int.J.Curr.Microbiol.App.Sci. 9(01): 2006-2013. doi: https://doi.org/10.20546/ijcmas.2020.901.227 